\title{
The Impact Of Instructor Attire On Student Perceptions Of Faculty Credibility And Their Own Resultant Behavior
}

Angeline M. Lavin, University of South Dakota, USA

Thomas L. Davies, University of South Dakota, USA

David L. Carr, University of South Dakota, USA

\begin{abstract}
Prior studies suggest that faculty members who are credible are more effective in the classroom in that they are evaluated more highly and their students achieve greater learning. This paper explores how the instructor's attire impacts his or her perceived credibility, and how the students' corresponding perception of instructor credibility impacts the students' self-described behavior. Questionnaires depicting instructors of both genders each wearing three different outfits, including casual, business casual and professional attire, are used to assess business student opinions regarding the academician's credibility and the students' resultant effort and learning. The results indicate that faculty members can take comfort in that their level of preparation, knowledge and ability to prepare students for a career do impact their credibility in the eyes of the students, no matter their choice of attire. Instructor credibility, in turn, was found to have a significant positive relationship with all ten student effort and behavior variables that were examined. In particular, credibility had the most impact on the student's preparation for each class, attentiveness, appreciation for instructor effort, and respect for the instructor. Positive significant relationships were also found between credibility and student evaluations of both the class and the instructor.
\end{abstract}

Keywords: Student effort, student behavior, student perceptions, faculty credibility, faculty attire

\section{INTRODUCTION}

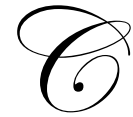

ollege professors today are expected to engage students and motivate them to take an active role in their own learning. Through their own academic preparation and subsequent scholarly efforts, most instructors are experts in the fields in which they teach. However, there is no guarantee that these "subject matter" experts will be able to impart this knowledge in such a way that students become more competent. Most would agree that the use of long oratories and less-than-inspired extended lectures as the primary source of knowledge transfer is less prevalent today. Students now expect engaging classroom environments, and academic institutions feel pressured to ensure that their faculty deliver what students want. Now, more than ever, the focal point of education is on student learning, and, fortunately, the professor's role in this process remains paramount. However, professors must adapt to changes in the learning environment in order to ensure that their message is relevant and accomplishes the transfer of knowledge.

The ultimate success of today's educator perhaps depends less on what he or she knows and more on his/her ability to inspire learning. Whether this is appropriate remains subject to debate. Nevertheless, the instructor traits and characteristics which translate into this requisite inspiration are subject to considerable discussion and study. At most colleges and universities, students are afforded the opportunity to evaluate the effectiveness of the professor through course evaluations. While the input obtained through course evaluations is weighted differently across academic institutions, it behooves all faculty members to gain some insight as to what he or she can do to positively impact the perceptions of the students enrolled on college campuses today, for his own benefit and that of 
the institution. The purpose of this paper is to first explore the factors that impact an instructor's credibility from the point of view of the students, and then to study how this credibility impacts the effort put forth by those students as well as their own learning-oriented behavior during the knowledge transfer process.

\section{PRIOR RESEARCH}

Student perceptions of faculty, typically formally captured through course evaluations, play a significant and growing role in academia. It is now commonplace for universities to utilize student ratings as part of the evaluation of teaching effectiveness. Chen and Hoshower (2003) report that student evaluations serve as both formative and summative measurements of teaching. Formative uses are more instructional-based, providing feedback to instructors who wish to change their teaching methodology or improve course content, format or structure. Summative uses are more administrative in nature; evaluations provide information relevant to promotion, tenure and pay decisions. The summative function also extends to the student's selection of instructors and courses. While prior studies have shown that properly designed student evaluations can provide valuable information when it comes to certain aspects of an instructor's teaching performance, considerable concern still remains over their overall validity and ultimate value. Nonetheless, "student evaluations have become routine at most colleges and universities" (Chen and Hoshower, 2003).

Given the importance and inevitability of student evaluations, faculty should be aware of those factors that potentially impact them since so much can be riding on their outcome. Studies have shown that perceived instructor credibility positively impacts perceptions of teaching effectiveness (Myers, 2004). According to McCroskey and Young (1981), credibility is defined as "the attitude toward a source of communication held at a given time by a communicator," or more simply, "believability." Perhaps not surprisingly, credibility is thought to be one of the most important variables affecting the instructor-student relationship (Myers, 2001). According to Cooper (1932), Aristotle believed ethos (i.e., credibility) consisted of three dimensions: intelligence, character and good will. Along this same line, Teven and McCroskey (1997) more recently postulated that credibility was comprised of three primary components, specifically competence, trustworthiness and perceived caring. Competence focuses on the instructor's perceived knowledge base or subject matter expertise (McCroskey, 1998). Trustworthiness centers around the goodness (e.g., honesty) of the professor (Frymier and Thompson, 1992), while caring involves the academician's expression of concern for the student's welfare (McCroskey, 1998).

Research has shown that instructor credibility benefits both the professor and student. Students who perceive their teacher as credible tend to be more motivated (Martin, Cheesebro, and Mottet, 1997), and report increased affective and cognitive learning (Johnson and Miller, 2002). In other words, Thweatt and McCroskey (1998) conclude that "the higher the credibility, the higher the learning." Students also tend to recommend credible instructors to others (Nadler and Nadler, 2001), respect them (Martinez-Egger and Powers, 2002), and evaluate them highly (Teven and McCroskey, 1997). Further, students perceive that these instructors better understand them (Schrodt, 2003), and are likely to take additional courses from them (Nadler and Nadler, 2001).

Certain instructor behaviors and strategies have been identified as enhancing student perceptions of teacher credibility in the classroom. For instance, those instructors who use appropriate amounts of technology (Schrodt and Turman, 2005), engage in out-of-classroom communication with their students (Myers, 2004), and are assertive and responsive (Martin et. al., 1997) are perceived to be more credible. Other studies have shown that faculty can increase their credibility by employing affinity-seeking strategies in their classes. Affinity, according to McCroskey and Wheeless (1976), is a "positive attitude toward another person." McCroskey and Wheeless proposed seven techniques to aid in affinity development: controlling physical appearance, increasing positive self-disclosure, stressing areas of positive similarity, providing positive reinforcement, expressing cooperation, complying with others' wishes, and fulfilling others' needs. In a subsequent study, McCroskey and McCroskey (1986) found the most frequently used strategies to enhance student affinity were physical attractiveness, sensitivity, elicit disclosure, trustworthiness and nonverbal immediacy.

Witcher, Onquegbuzie, Collins, Filer, Wiedmaier, and Moore (2003) suggested that college students believe effective college teaching involves the following nine characteristics, listed in order of importance: (1) student-centered; (2) knowledgeable about the subject matter; (3) professional; (4) enthusiastic about teaching; (5) 
effective at communication; (6) accessible; (7) competent at instruction; (8) fair and respectful; and (9) provider of adequate performance feedback. With little effort, many of these characteristics can be linked to one of the aforementioned three dimensions of credibility. As a result, instructors likely possess the ability to modify their own behavior and utilize pedagogical tools in such a way to improve their credibility as well as student perceptions of their teaching prowess.

As mentioned, physical appearance, attractiveness and professionalism have been identified as factors that have the potential to impact student perceptions of the instructor. These prior studies raise the specific question of whether the attire worn by a faculty member in the classroom can impact student perceptions of the instructor's credibility and, thus, their teaching effectiveness. Molloy $(1975,1977)$ postulated that clothing impacts or influences four kinds of judgments, including credibility, likeability, interpersonal attractiveness, and dominance, and, thus, acts as a primary impression management tool. Impression management involves a person's "conscious attempt to exercise conscious control over selected communicative behaviors and cues - particularly nonverbal cues, for purposes of making a desired impression" (Leathers, 1992).

In academia, studies generally have found that instructors who dress more formally are perceived as being knowledgeable, organized and well-prepared, while more casually dressed instructors are generally perceived as being friendly, flexible and sympathetic (Rollman, 1980). Lukavsky, Butler and Harden (1995) studied the impact of attire on the personal characteristics of approachability, flexibility, and respect. They found significant differences in student perceptions of those three characteristics based on whether the instructor was formally or informally dressed. The instructor who dressed informally was rated most approachable and flexible, but at the same time commanded the least amount of respect.

A few other studies have considered various aspects of attire in an academic setting, and the overall conclusion that can be reached is that formal or professional attire is generally the most positively perceived by students (e.g., Harris et al., 1983; Bassett, 1979). A study of 318 college students by Kwon and Johnson-Hillery (1998) indicated that the students rated individuals who were dressed in formal business attire more positively on a variety of occupational attributes (such as knowledgeable, competent, credible, businesslike, responsible, trustworthy, and efficient) than individuals who were dressed either semi-formally or informally. Sebastian and Bristow (2008) found that students attribute more expertise to professors who are dressed formally, but they also rank formally dressed professors lower in terms of likeability than casually dressed professors.

This study has several purposes. It seeks to determine what instructor traits or characteristics influence student perceptions of instructor credibility, and whether the attire of the faculty member influences these perceptions. In addition, the authors seek to determine how the instructor's "attire-dependent" perceived credibility impacts student behaviors. A two-stage least squares approach is employed, where the first stage examines the determinants of perceived credibility, and the second stage explores how this perceived credibility affects student behavior.

\section{PRESENT STUDY}

Students taking select classes at a mid-sized Midwestern university business school were asked to participate in a research study by completing a questionnaire, the purpose of which was to assess how a professor's clothing choice in the classroom might impact their perceptions of the instructor' credibility, and how this perception would impact their own effort and behavior. The first page of the survey was a cover sheet that included three high quality color photos of either the same female or male instructor wearing three different outfits representing professional, business casual and casual attire. The models depicted were not actual faculty members so as to prevent any potential bias based on personal familiarity with the instructor. Two different variations of each of the surveys were used to change the order in which the attire was presented. In one case the instructor was depicted wearing casual, business casual and professional dress (Version 1) respectively, while in the second version the same instructor was depicted wearing professional, business casual and casual clothing (Version 2). Both variations of each version of the survey (male or female model) were randomly administered in each class section to obtain a cross section of responses. 
Students in the chosen classes were asked how the professor's dress impacted their perceptions in general with respect to several instructor and instruction-related questions. Survey questions were patterned after three different student evaluation forms used at one time at the authors' institution. Students were informed that the study was not meant to be an evaluation of any particular instructor. As part of the survey, it was stipulated that the instructor's attire was a matter of personal preference that could depend upon a number of factors including classroom conditions (e.g., heating, cooling and ventilation), the class setting (e.g., evening class, length of class session), delivery mode (e.g., face to face versus distance) and his or her individual preferences and comfort. It should be noted that while faculty are encouraged to dress professionally when teaching at this university, no dress code exists. So while some variation does exist, faculty attire does tend to fall on the more professional side.

The survey instrument consisted of several parts including multiple substantive and demographic questions. Students were asked how the professor's various styles of dress would influence their perceptions of the instructor's qualifications and ability to teach, as well as the overall quality of the course, program and institution. Specific questions were as follows:

\section{Instructor Characteristics that May Impact Credibility}

Q1. His/her level of preparation for class.

Q2. His/her knowledge of the material (i.e., subject matter).

Q3. His/her ability to present information clearly and in an understandable manner.

Q4. His/her ability to relate course material to the real world.

Q5. His/her ability to stimulate students to intellectual effort beyond what is typically required.

Q6. His/her concern for student learning.

Q7. His/her willingness to answer questions and listen to student opinions.

Q8. His/her ability to prepare students for a career.

Q9. His/her professionalism.

\section{Instructor Credibility}

Q10. His/her credibility.

\section{Student Effort and Behavior}

Q11. His/her level of participation for each class.

Q12. His/her attentiveness in class.

Q13. His/her level of participation in class discussions.

Q14. His/her class attendance.

Q15. His/her willingness to ask the instructor questions during class.

Q16. His/her amount learned from class.

Q17. His/her appreciation for the instructor's efforts.

Q18. His/her appreciation for the importance of the material.

Q19. His/her desire to take additional classes from the instructor.

Q20. His/her level of respect for the instructor.

Q21. His/her overall evaluation of the class.

Q22. His/her overall evaluation of the instructor.

In addition, students were asked a number of demographic questions, including whether they were graduate or undergraduate students, their program of study or major, and their year in school (e.g., freshman, sophomore, etc.) as well as their grade point average, gender, age, and personality type.

In all, 15 business instructors, including five female and 10 male faculty members administered the survey in their classes. The faculty members were selected in part on the basis of both their discipline and their gender in order to provide a cross-section of courses being evaluated. Classes chosen included those at the 100 (first year), 200 (second year), 300 (junior level), 400 (senior level) and graduate (700) level. Courses were selected from several 
majors offered by the business school, including accounting, finance, and management at the undergraduate level as well as from the MBA and MPA (Master of Professional Accountancy) programs. The survey was administered in 13 different classes, including multiple sections of several of the courses offered on the university's main campus and in a satellite location, resulting in a total of 23 sections being studied.

The survey was administered near the midpoint of the fall 2008 semester. Since it was probable that there was some overlap in enrollment for these classes, students were asked to complete the same version of the survey only once, as it was not designed to be course dependent. However it was possible for the same student to answer multiple versions of the questionnaire (i.e., different gender of the model as well as the order of presentation of the model) if enrolled in different classes included as part of the study. Faculty members who participated were asked to devote class time to allow students to complete the survey due to the predicted positive impact on the response rate. In total, 454 usable responses were obtained from undergraduate business students, the focus of this particular study.

A summary of the demographic information is presented in Appendix A at the end of the article. The genders of the business students who responded were fairly evenly split between female and male, with 216 (47.6\%) female respondents and 237 (52.2\%) male respondents; one of the 454 students left the question blank. About $72 \%$ of the respondents were 21 years old or younger, and $78.4 \%$ of the respondents indicated that they were "traditional" students. Forty percent of the respondents were freshmen or sophomores, and about $60 \%$ of the respondents were from rural areas. Nearly $60 \%$ of the respondents reported a grade point average above 3.0.

\section{RESULTS}

The purpose of this paper is threefold. The study seeks to determine what instructor traits or characteristics influence student perceptions of the faculty member's credibility. In addition, the project also seeks to determine whether the attire of the faculty member (casual, business causal or professional) influences these perceptions. The authors also attempted to determine how the instructor's perceived attire-dependent credibility impacts student effort and behavior. A two-stage least squares approach is employed, where the first stage examines the determinants of perceived credibility, and the second stage explores how perceived credibility affects student behavior.

\section{First Stage - Factors that Impact Credibility}

Each of the 454 survey respondents was asked to indicate how the style of faculty attire might impact the student's perception of each trait included in questions 1-10 above. The responses were first disaggregated by type of dress, resulting in 424 responses to the picture of the faculty member dressed in casual attire, 427 responses to the picture of the faculty member dressed in business casual attire, and 431 responses to the faculty member dressed in professional attire. Surveys that had no response for the relevant questions were dropped. The data collected for questions 1-9 above for each of the three samples (casual, business casual and professional) were tested for multicollinearity. Multi-collinearity (correlations above 0.70) was found in all three samples among the variables represented by questions 3, 5, and 9, which asked about the instructor's ability to present information clearly, stimulate intellectual effort beyond what is typically required, and his/her professionalism. The multi-collinearity resulted from the similarity of the questions. For example, questions 8 and 9 ask about the instructor's ability to prepare students for a career and the instructor's professionalism, respectively. Question 3, which asked about the instructor's ability to present information in a clear and understandable manner, was highly correlated with question 2 (the instructor's knowledge of the material) and question 4 (the instructor's ability to relate course material to the real world). The data for questions 3, 5 and 9 were then removed from each of the three samples, and each sample was again tested for multi-collinearity. This second test showed that all remaining correlations were below 0.7 for the data from questions 1, 2, 4, 6, 7, and 8. Therefore, those questions were included as the independent variables in the OLS regression model and are represented by the variable $Q$ in the equation below. The dependent variable, $\mathrm{Q}_{10}$, is credibility. The beta coefficients explain the relationship between each of the included instructor characteristics and credibility.

$Q_{10}=b_{0}+b_{1} Q_{1}+b_{2} Q_{2}+b_{3} Q_{4}+b_{4} Q_{6}+b_{5} Q_{7}+b_{6} Q_{8}+\varepsilon_{i}$ 
The results of the regression analysis are presented in Table 1. The $\mathrm{R}^{2}$ measure reported for each model suggests that the independent variables or traits included in the casual dress sample explain approximately $50 \%$ of the variability in the credibility, the dependent variable, while the variables or traits explain more than $60 \%$ of the variability in credibility for the business casual and professional attire samples. Furthermore, the intercept is significant for the casual sample, which suggests that there are other traits which would help explain credibility in the case of casually dressed instructor. The intercepts for the business casual and professional samples were not significant.

Table 1: Instructor Characteristics that Impact Credibility

\begin{tabular}{|c|c|c|c|}
\hline & $\begin{array}{c}\text { Casual Sample } \\
\text { Coefficient }\end{array}$ & $\begin{array}{c}\text { Business Casual } \\
\text { Sample Coefficient }\end{array}$ & $\begin{array}{c}\text { Professional } \\
\text { Sample Coefficient }\end{array}$ \\
\hline $\mathrm{R}^{2}$ & 0.499 & 0.626 & 0.631 \\
\hline Intercept & $0.371 *$ & 0.081 & 0.023 \\
\hline Q1 - Level of preparation & $0.141 *$ & $\mathbf{0 . 0 8 2} * * *$ & $0.083 * * *$ \\
\hline Q2 - Knowledge of the subject matter & 0.218* & 0.123* & $0.269 *$ \\
\hline Q4 - Ability to relate course material to the real world & 0.024 & $0.166 *$ & 0.071 \\
\hline Q6 - Concern for student learning & 0.010 & $0.082 * * *$ & -0.004 \\
\hline Q7 - Willingness to answer questions and listen & 0.113* & $0.099 * *$ & 0.052 \\
\hline Q8 - Ability to prepare students for a career & 0.391* & $0.395 *$ & $0.502 *$ \\
\hline
\end{tabular}

* Significant at the $1 \%$ level

** Significant at the $5 \%$ level

*** Significant at the $10 \%$ level

According to the results presented in Table 1, the traits that have significant impact on credibility regardless of the attire of the faculty member are the instructor's level of preparation, knowledge of the subject matter, and ability to prepare students for a career. While the instructor's level of preparation was significant across all three samples, the significance level varied. The instructor's preparation was significant at the $1 \%$ level when the faculty member was dressed in casual attire, but it was significant at only the $10 \%$ level for the business casual and professional attire samples. This difference in significance level suggests that an instructor's level of preparation is much more important for a casually dressed instructor than for one dressed in business casual or professional attire. In other words, instructors who dress in casual attire may need to be better prepared in order to achieve the same level of credibility as an instructor dressed in business casual or professional attire.

The instructor's knowledge of the subject matter and ability to prepare students for a career were significant at the $1 \%$ level across all three samples, which suggests that of all the traits used in this model, these are the most significant predictors of instructor credibility. It is interesting to note that two additional instructor traits, the ability to relate course material to the real world and concern for student learning, were significant predictors of credibility only in the case of the instructor dressed in business casual attire. Also of interest, the ability to relate course material to the real world was significant at the $1 \%$ level for the business casual sample, but was not significant for the casual or professional samples.

An instructor's willingness to answer questions and listen to student opinions was significant at the 5\% level for the casual attire sample and at the $10 \%$ level for the business casual sample, but it was not significant for the professional sample. This result suggests that instructors who dress more casually are more credible if they are willing to answer questions and listen to student opinions. The explanation of this finding may be that casually dressed instructors are perceived by the students to impart knowledge via discussion, while professional dressed instructors are perceived to impart knowledge in the more traditional lecture setting. This finding is interesting in light of previous studies by the authors of this paper which suggest that students perceive that instructors dressed in more casual attire are more willing to answer questions and listen to student opinions.

To summarize, the three traits that have the most impact on instructor credibility are their level of preparation, knowledge of the subject matter, and ability to prepare students for a career. Additionally, the results of the first stage of this regression analysis suggest that attire does impact students' perception of credibility, as the 
impact of some traits on credibility does in fact vary depending on the instructor's attire. The traits mentioned are the only three that have a significant impact on the credibility of a professional dressed instructor, but all six traits tested impact the credibility of an instructor dressed in business casual attire. Further, four of the six traits have a significant impact on the credibility of a professor dressed in casual attire. The differentiating trait for casual versus professional attire is the instructor's ability to answer questions and listen to student opinions, which may suggest that students expect casually dressed instructors to conduct class using more discussion or knowledge discovery, while professionally dressed instructors are expected to "impart" more knowledge on the students.

\section{Second Stage - The Impact of Credibility on Student Effort and Behavior}

The purpose of the second stage of this analysis was to study the impact of instructor credibility on student effort and behavior, as impacted by faculty choice of attire. A traditional two-stage least squares regression was conducted for this analysis, where the model developed in the first stage OLS regression was used to obtain the estimated value of the dependent variable (credibility). The estimated value for credibility is represented by $\hat{Q}_{10}$ in the second stage OLS model. These estimated values for credibility were then used as the independent variable in the second stage regression to determine the relationship between credibility and the student effort and behavior information that was collected in survey questions 11-22. The second stage model contained one regression for each of the twelve questions (Q11-Q22), and the twelve separate student effort and behavior variables were the independent variables in each regression. As in the first stage, three separate samples based on different attire were analyzed to determine how student behavior was impacted by the level of instructor credibility and influenced by the instructor's attire. In total, the second stage model contains 36 estimations. The following model was used to analyze the data in the second stage:

$Q_{i=11 \text { to } 22}=b_{0}+b_{i} * \hat{Q}_{10}+\varepsilon_{i}$

The results of the second stage regression analysis are presented in Table 2. The second stage regressions were run as single variable regressions to determine whether credibility impacted the ten aspects of student effort and behavior as well as the course and instructor evaluation questions that were captured in the answers to survey questions 11 through 22. All coefficients on all the effort and behavior variables across all three styles of dress were positive and significant at the $1 \%$ level, which suggests that credibility has a significant impact on student effort and behavior as well as the overall evaluation of the class and the instructor. In essence, the more credible the instructor is in the eyes of the student, the greater their effort, the more positive their behavior, and the higher the overall evaluation of both the class and the instructor.

Of interest is the difference in the $\mathrm{R}^{2}$ measure among questions and across the three styles of dress. Since all of the coefficients were highly significant for all of the behavior/effort variables, the $\mathrm{R}^{2}$ measures can help to discern the underlying impact of credibility on the student behavior/effort variables across the three attire samples. The $\mathrm{R}^{2}$ for the casual attire sample varies from 0.343 to 0.103 as indicated in Table 2 . While $34 \%$ of a student's attentiveness is explained by instructor credibility, only $10 \%$ of the willingness of students to ask questions is explained by instructor credibility. The $\mathrm{R}^{2}$ values for the business casual attire sample are much higher overall, ranging from 0.444 to 0.265 . In the case of this sample, $44 \%$ of a students' appreciation for instructor effort was explained by credibility, while $26.5 \%$ of the "willingness of students to ask questions" was explained by instructor credibility. The trend continued in the professional attire sample, with "willing to ask questions" having the lowest $\mathrm{R}^{2}$ value at $8.5 \%$, and "appreciation for instructor effort" having the highest $\mathrm{R}^{2}$ value at $43.4 \%$.

Across the three types of attire, credibility explained the most variability in "overall evaluation of the instructor" for the professional attire sample, although the $\mathrm{R}^{2}$ for the business casual dress sample was quite high as well. The results were similar for "overall evaluation of the course", with credibility explaining about $33 \%$ of the variability in that item for both the professional and business casual samples. These findings are consistent with those of Teven and McCroskey (1997) who found that students rate credible instructors highly, and Myers (2004) who found that credibility positively impacts perceptions of teaching effectiveness. In contrast, credibility explained much less of the variation in both the class and instructor evaluations for the casual clothing sample relative to the other two samples. 
Table 2: The Relationship between Student Effort/Behavior Variables and Instructor Credibility

\begin{tabular}{|l|c|c|c|c|c|c|}
\hline & \multicolumn{2}{|c|}{ Casual Sample } & \multicolumn{2}{c|}{ Business Casual Sample } & \multicolumn{2}{c|}{ Professional Sample } \\
\hline Question & Coefficient & $\mathrm{R}^{2}$ & Coefficient & $\mathrm{R}^{2}$ & Coefficient & $\mathrm{R}^{2}$ \\
\hline Q11 -Level of Preparation for Each Class & $0.781^{*}$ & 0.325 & $0.737^{*}$ & 0.418 & $0.672^{*}$ & 0.394 \\
\hline Q12 - Attentiveness & $0.806^{*}$ & 0.343 & $0.759^{*}$ & 0.430 & $0.607^{*}$ & 0.315 \\
\hline $\begin{array}{l}\text { Q13 - Level of Participation in Class } \\
\text { Discussions }\end{array}$ & $0.614^{*}$ & 0.179 & $0.624^{*}$ & 0.334 & $0.377^{*}$ & 0.129 \\
\hline Q14 - Attendance & $0.569^{*}$ & 0.184 & $0.628^{*}$ & 0.318 & $0.560^{*}$ & 0.297 \\
\hline Q15 - Willing to Ask Questions & $0.514^{*}$ & 0.103 & $0.570^{*}$ & 0.265 & $0.309^{*}$ & 0.085 \\
\hline Q16 - Amount Learned & $0.561^{*}$ & 0.235 & $0.563^{*}$ & 0.303 & $0.506^{*}$ & 0.293 \\
\hline Q17 - Appreciation for Instructor Effort & $0.760^{*}$ & 0.320 & $0.814^{*}$ & 0.444 & $0.749^{*}$ & 0.434 \\
\hline Q18 - Appreciation of Material & $0.612^{*}$ & 0.267 & $0.622^{*}$ & 0.335 & $0.579^{*}$ & 0.332 \\
\hline $\begin{array}{l}\text { Q19 - Desire to take Additional Classes in } \\
\text { Subject Matter }\end{array}$ & $0.776^{*}$ & 0.331 & $0.675^{*}$ & 0.369 & $0.511^{*}$ & 0.256 \\
\hline Q20 - Respect for Instructor & $0.757^{*}$ & 0.306 & $0.798^{*}$ & 0.397 & $0.759^{*}$ & 0.419 \\
\hline Q21 - Overall evaluation of the class & $0.580^{*}$ & 0.247 & $0.652^{*}$ & 0.338 & $0.582^{*}$ & 0.330 \\
\hline Q22 - Overall evaluation of the instructor & $0.645^{*}$ & 0.231 & $.0 .707^{*}$ & 0.350 & $0.689^{*}$ & 0.379 \\
\hline
\end{tabular}

* Significant at the $1 \%$ level

Table 3 provides a ranking of the $\mathrm{R}^{2}$ values for each student behavior/effort variable in each of the three samples (Questions 11 through 20). The ranking goes from the highest $\mathrm{R}^{2}$ value (\#1) to the lowest $\mathrm{R}^{2}$ value (\#10). As can be seen, credibility explains the most variability in "attentiveness" for the casual sample, and in "appreciation for instructor effort" for both the business casual and professional samples. Credibility explains the least variability in "willing to ask questions" across all three samples.

Looking at the results in more detail, instructor credibility consistently explained the most variability in the following four student behavior/effort variables across all three samples:

- Q11 - Level of Preparation for Each Class

- $\quad$ Q12 - Attentiveness

- $\quad \mathrm{Q} 17$ - Appreciation for Instructor Effort

- $\quad$ Q20 - Level of Your Respect for the Instructor

Alternatively stated, credibility has the most impact on student class preparation, student attentiveness, student appreciation for instructor effort, and the student's respect for the instructor. These findings are consistent with Martinez-Egger and Powers (2002) who found that students respect credible instructors and tend to be more motivated by credible teachers (Martin, Cheesebro, and Mottet, 1997).

In contrast, instructor credibility consistently explains the least variability and, therefore, has the least impact on the following four student behavior/effort variables across all three samples:

- $\quad$ Q13 - Level of Participation in Class Discussions
- $\quad$ Q14 - Attendance
- $\quad$ Q15 - Willing to Ask Questions
Q16 - Amount Learned

It is interesting to note that students do not seem to perceive that instructor credibility impacts the amount learned as much as credibility impacts other behavior and effort variables, such as the student's level of preparation for class and attentiveness. Studies including Thweatt and McCroskey (1998) and Johnson and Miller (2002) did find that credible faculty members do have a positive impact on learning. In contrast, the student perceptions captured in this study are not strongly in agreement with that relationship. 
Table 3: Relative Explanatory Ability of Credibility on Student Effort and Behavior

\begin{tabular}{|c|c|c|c|c|c|}
\hline \multicolumn{2}{|l|}{ Casual Sample } & \multicolumn{2}{|c|}{ Business Casual Sample } & \multicolumn{2}{|l|}{ Professional Sample } \\
\hline Question & $\mathrm{R}^{2}$ Rank & Question & $\mathrm{R}^{2}$ Rank & Question & $\mathrm{R}^{2}$ Rank \\
\hline Q12 - Attentiveness & 1 & $\begin{array}{l}\text { Q17 - Appreciation for } \\
\text { Instructor Effort }\end{array}$ & 1 & $\begin{array}{l}\text { Q17 - Appreciation for } \\
\text { Instructor Effort }\end{array}$ & 1 \\
\hline $\begin{array}{l}\text { Q19 - Desire to Take } \\
\text { Additional Classes in the } \\
\text { Subject Matter }\end{array}$ & 2 & Q12 - Attentiveness & 2 & Q20 - Respect for Instructor & 2 \\
\hline $\begin{array}{l}\text { Q11 - Level of Preparation } \\
\text { for Each Class }\end{array}$ & 3 & $\begin{array}{l}\text { Q11 - Level of Preparation } \\
\text { in Each Class }\end{array}$ & 3 & $\begin{array}{l}\text { Q11 - Level of Preparation in } \\
\text { Each Class }\end{array}$ & 3 \\
\hline $\begin{array}{l}\text { Q17 - Appreciation for } \\
\text { Instructor Effort }\end{array}$ & 4 & $\begin{array}{l}\text { Q20 - Respect for } \\
\text { Instructor }\end{array}$ & 4 & $\begin{array}{l}\text { Q18 - Appreciation of } \\
\text { Material }\end{array}$ & 4 \\
\hline $\begin{array}{l}\text { Q20 - Respect for } \\
\text { Instructor }\end{array}$ & 5 & $\begin{array}{l}\text { Q19 - Desire to Take } \\
\text { Additional Classes in the } \\
\text { Subject Matter }\end{array}$ & 5 & Q12 - Attentiveness & 5 \\
\hline $\begin{array}{l}\text { Q18-Appreciation of } \\
\text { Material }\end{array}$ & 6 & $\begin{array}{l}\text { Q18-Appreciation of } \\
\text { Material }\end{array}$ & 6 & Q14 - Attendance & 6 \\
\hline Q16 - Amount Learned & 7 & $\begin{array}{l}\text { Q13 - Level of } \\
\text { Participation in Class } \\
\text { Discussions }\end{array}$ & 7 & Q16 - Amount Learned & 7 \\
\hline Q14-Attendance & 8 & Q14-Attendance & 8 & $\begin{array}{l}\text { Q19 - Desire to Take } \\
\text { Additional Classes in the } \\
\text { Subject Matter }\end{array}$ & 8 \\
\hline $\begin{array}{l}\text { Q13 - Level of } \\
\text { Participation in Class } \\
\text { Discussions }\end{array}$ & 9 & Q16 - Amount Learned & 9 & $\begin{array}{l}\text { Q13 - Level of Participation } \\
\text { in Class Discussions }\end{array}$ & 9 \\
\hline $\begin{array}{l}\text { Q15 - Willing to Ask } \\
\text { Questions }\end{array}$ & 10 & $\begin{array}{l}\text { Q15-Willing to Ask } \\
\text { Questions }\end{array}$ & 10 & $\begin{array}{l}\text { Q15-Willing to Ask } \\
\text { Questions }\end{array}$ & 10 \\
\hline
\end{tabular}

"Appreciation of the importance of the material" (Question 18) falls within the middle in all three samples in terms of how much of its variability is explained by credibility. The ability of credibility to explain a student's "desire to take additional classes in the subject matter" (Question 19) is quite high for the casual sample, somewhat lower for the business casual sample, and near the bottom for the professional sample.

In summary, the analysis conducted in the second stage of this model found significant positive relationships between credibility and all ten student effort/behavior variables across all three attire samples. Furthermore, the $\mathrm{R}^{2}$ values suggest that credibility explains the most variability in the student's preparation for each class, attentiveness, appreciation for instructor effort, and respect for the instructor.

\section{CONCLUSION}

This study suggests that certain instructor-related traits have a significant impact on credibility regardless of the attire of the faculty member. However, there is a difference in the significance level of some the traits depending on how formally or informally the professor dresses.

The analysis conducted in the second stage of this model found significant positive relationships between credibility and all ten student effort/behavior variables across all three attire samples. Therefore, the credibility of the faculty member in the eyes of the students does have an impact on the way they act in class as well as their behavior both inside and outside the classroom. The $\mathrm{R}^{2}$ values suggest that credibility explains the most variability in the student's preparation for each class, attentiveness, appreciation for instructor effort, and respect for the instructor. Furthermore, there are also significant positive relationships between credibility and student evaluations of both the class and the instructor. For the professional and business casual samples, credibility explains between 33 and $37 \%$ of class and instructor evaluation. 
The results of this study are based only on data collected at one business school at a small Midwestern university and may not be generalized to broader populations of students. However, this initial works lays the groundwork for further study at other universities or across other colleges within this university. Faculty members can take comfort that their level of preparation, knowledge and ability to prepare students for a career do positively impact their credibility. Credibility, in turn, positively impacts student effort and behavior.

\section{AUTHOR INFORMATION}

Angeline Lavin is a professor of finance and the director of graduate programs at the University of South Dakota's Beacom School of Business. She received her Ph.D. in finance from the University of Nebraska-Lincoln, and she also holds the Chartered Financial Analyst (CFA) designation. Her current research interests, in addition to pedagogical issues, include the signaling value of independent auditors' opinions, earnings restatements, and exchange traded funds (ETFs). She has published in the Journal of Financial Services Research, the Journal of Economic Education, the Journal of Financial Research, the Journal of Real Estate Finance and Economics, and Financial Practice in Education.

Thomas Davies is a professor of accounting at the University of South Dakota's Beacom School of Business. He received his J.D. from the University of South Dakota School of Law and LL.M. in Taxation from the University of Missouri - Kansas City. He also holds the Certified Public Account (CPA) designation. His current research interests, in addition to pedagogical issues, include tax policy implications and earnings restatements. He has recently published in the Journal of Forensic Accounting, the Journal of Accounting and Finance Research, and the College Student Journal.

David Carr is an assistant professor of economics at the University of South Dakota's Beacom School of Business. He received his Ph.D. from the University of Colorado-Boulder. His current research interests include the economics of multinational firms and environmental regulations, the impact of market structure on industry competition, and pedagogical issues. He has published in the American Economic Review and has articles forthcoming in the International Journal of Management and the College Student Journal.

\section{REFERENCES}

1. Bassett, R., Effects of Source Attire on Judgments of Credibility, Central States Speech Journal, Vol. 30, pp. 282-285, 1979.

2. Chen, Y. and and L. Hoshower, Student Evaluation of Teaching Effectiveness: as assessment of student perception and motivation, Assessment \& Evaluation in Higher Education, Vol. 28, No. 1, pp. 71 -87, 2003.

3. Cooper, L. The Rhetoric of Aristotle. New York: Appleton-Century-Crofts, 1932.

4. Frymier, A. and C. Thompson. Perceived Teacher Affinity Seeking in Relation to Perceived Teacher Credibility, Communication Education, Volume 41, pp. 388-399, October 1992.

5. Harris, M., J. James, J. Chavez, M. Fuller, S. Kent, C. Massanari, C. Moor, and F. Walsh, Clothing: Communication, Compliance and Choice, Journal of Applied Psychology, Vol. 13, pp. 88-97, 1983.

6. Johnson, S. and A. Miller, A Cross-Cultural Study of Immediacy, Credibility, and Learning in the U.S. and Kenya, Communication Education, Vol. 51, No. 3, pp. 280-292, 2002.

7. Kwon, Y. and J. Johnson-Hillery, College Students' Perceptions of Occupational Attributes Based on Formality of Business Attire, Perceptual and Motor Skills, Vol. 87, pp. 987-994, 1998.

8. Leathers, D., Successful Nonverbal Communication, Macmillan, New York, New York, 1992.

9. Lukavsky, J., S. Butler and A. Harden, Perceptions of an Instructor: Dress and Students' Characteristics, Perceptual and Motor Skills, Vol. 81, pp. 231-240, 1995.

10. Martin, M., J. Cheesebro and T. Mottet, Students' Perceptions of Instructors' Socio-Communicative Style and the Influence on Instructor Credibility and Situational Motivation. Communication Research Reports, Vol. 14, pp, 431-440, 1997.

11. Martinez-Egger, A. and W. Powers, Student Respect for a Teacher: Measurement and Relationships to Teacher Credibility and Classroom Behavior Perceptions. Paper presented at the annual meeting of the National Communication Association, New Orleans, LA, 2002. 
12. McCroskey, J. and L. Wheeless, Introduction to Human Communication. Boston, MA: Allyn and Bacon, 1976.

13. McCroskey, J. and T. Young, Ethos and Credibility: The Construct and Its Measurement after Three Decades, Central States Speech Journal, Vol. 32, 24-34, 1981.

14. Molloy, J. Dress for Success Warner Books, New York, New York, 1975.

15. Molloy, J. The Woman's Dress for Success. Follett, Chicago, Illinois 1977.

16. Myers, S., The Relationship between Perceived Instructor Credibility and College Student in-class and Out-of-class Communication, Communication Reports, Vol. 17, No. 2, pp. 129-137, Summer 2004.

17. Nadler, M. and L. Nadler, The Roles of Sex, Empathy and Credibility in Out-of-Class Communication between Faculty and Students, Women's Studies in Communication, Vol. 24, pp.241-261, 2001.

18. Rollman, S., Some Effects of Teachers' Style of Dress. Paper presented at the Southern Speech Communication Association Annual Meeting, 1980.

19. Schrodt, P., Students' Appraisals of Instructors as a Function of Students' Perceptions of Instructors' Aggressive Communication, Communication Education, Vol. 41, pp. 311-324, 2003.

20. Schrodt, P. and P. Turman, The Impact of Instructional Technology Use, Course Design, and Sex Differences on Students' Initial Perceptions of Instructor Credibility, Communication Quarterly, Vol. 53, No. 2, pp. 177-196, 2005.

21. Schrodt, P. and P. Witt. Students' Attributions of Instructor Credibility as a Function of Students' Expectations of Instructional Technology Use and Nonverbal Immediacy, Communication Education, Vol. 55, No. 1, pp. 1-20, January 2006.

22. Sebastian, R. and D. Bristow, Formal or Informal? The Impact of Style of Dress and Forms of Address on Business Students' Perceptions of Professors, Journal of Education for Business, March/April, pp. 196201, 2008.

23. Teven, J. and J. McCroskey. The Relationship of Perceived Teacher Caring with Student Learning and Teacher Evaluation, Communication Education, Vol. 46., No. 1, pp. 1-9, 1997.

24. Thweatt, K. and J. McCroskey, The Impact of Teacher Immediacy and Misbehaviors on Teacher Credibility, Communication Education, Vol. 47, pp. 348-358, 1998.

25. Witcher, A., A. Onquegbuzie, K. Collins, J. Filer, C. Wiedmaier, and C. Moore, Students' Perceptions of Characteristics of Effective College Teachers, 2003. Retrieved from the ERIC Database ED 482517, Microfiche Edition, in November 2007. 


\section{Appendix A: Demographic Information}

\begin{tabular}{|c|c|c|}
\hline Accounting & 94 & $20.7 \%$ \\
\hline Economics & 22 & $4.8 \%$ \\
\hline Finance & 73 & $16.1 \%$ \\
\hline Health Services & 50 & $11.0 \%$ \\
\hline Management & 115 & $25.3 \%$ \\
\hline Marketing & 47 & $10.4 \%$ \\
\hline Business Undeclared & 53 & $11.7 \%$ \\
\hline Non-Business & 0 & $0.0 \%$ \\
\hline Senior & 95 & $20.9 \%$ \\
\hline Junior & 174 & $38.3 \%$ \\
\hline Sophomore & 142 & $31.3 \%$ \\
\hline Freshmen & 40 & $8.8 \%$ \\
\hline Blanks & 3 & $0.7 \%$ \\
\hline $3.51-4.00$ & 121 & $26.7 \%$ \\
\hline $3.01-3.50$ & 172 & $37.9 \%$ \\
\hline $2.51-3.00$ & 124 & $27.3 \%$ \\
\hline $2.01-2.50$ & 27 & $5.9 \%$ \\
\hline 2.00 Or Lower & 4 & $0.9 \%$ \\
\hline Blanks & 6 & $1.3 \%$ \\
\hline Female & 216 & $47.6 \%$ \\
\hline Male & 237 & $52.2 \%$ \\
\hline Blanks & 1 & $0.2 \%$ \\
\hline Over 24 & 46 & $10.1 \%$ \\
\hline $22-24$ & 80 & $17.6 \%$ \\
\hline $19-21$ & 305 & $67.2 \%$ \\
\hline 18 Or Younger & 21 & $4.6 \%$ \\
\hline Blanks & 2 & $0.4 \%$ \\
\hline Traditional Student & 356 & $78.4 \%$ \\
\hline Non-Traditional Student & 95 & $20.9 \%$ \\
\hline Blanks & 3 & $0.7 \%$ \\
\hline Rural & 272 & $59.9 \%$ \\
\hline Urban & 176 & $38.8 \%$ \\
\hline Blanks & 6 & $1.3 \%$ \\
\hline
\end{tabular}

